\title{
Teachers' Characteristics as Correlates of Students' Academic Performance among Secondary School Students in Saki-west Local Government Area of Oyo State
}

\author{
Fehintola, J.O. \\ Dept. of Guidance and Counselling \\ University of Ibadan, Ibadan, Nigeria \\ EMail: jof677@yahoo.com, joseph.fehintola@gmail.com
}

\author{
Doi:10.5901/jesr.2014.v4n6p459
}

\begin{abstract}
This study examined relationship among teachers academic qualification, teachers professional qualification, teachers content knowledge, teachers instructional quality, teachers' evaluation procedures, teachers' work value, teachers' classroom attendance' and teachers' job satisfaction on academic performance of secondary school students in Saki-west local government area. The study adopted a descriptive research design of correlational type. The secondary school teachers in Saki township were selected using multi-stage sampling technique and 718 teachers were selected at random for the study out of 2456 teachers working in this local government. The Teacher's characteristics scale $(\alpha=0.86)$ was used as a measure of teacher's characteristics factor. Three research questions were answered in the study. Correlation and Multiple Regression were used as tools of analysis. The eight variables (teachers academic qualification, teachers professional qualification, teachers content knowledge, teachers instructional quality, teachers' evaluation procedures, teachers' work value, teachers' classroom attendance' and teachers' job satisfaction) when combined, accounted for $54.6 \%$ of the total variance in the academic performance. There was also significant relative contribution of the independent variables (teachers academic qualification, teachers content knowledge, teachers instructional quality, teachers' evaluation procedures and teachers' job satisfaction) to academic performance of the participants $\left.\left(F_{(8,710}\right)=47.48 ; p<0.05\right)$. Also, the teachers content knowledge made the most significant relative contribution to the prediction of academic performance $(B=0.544, t=7.692, p<0.05)$; followed by teachers instructional quality $(B=0.531, t=12.767, p<0.05)$; teachers academic qualification $(B=0.445, t=5.696, p<0.05)$, followed by teachers evaluation procedures $(B=0.405, t=3.924, p<0.05)$ and then, teachers job satisfaction $(B=0.176, t=2.369$, p $<0.05)$. However, teachers' professional qualification, teachers work value and teachers classroom attendance were not potent predictors of academic performance of secondary school students in the surveyed local government area. The eight independent variables (teachers academic qualification, teachers professional qualification, teachers content knowledge, teachers instructional quality, teachers' evaluation procedures, teachers' work value, teachers' classroom attendance' and teachers' job satisfaction) considered in this study were potent factors to academic performance of secondary school students in the study area. Based on these findings, teacher's content knowledge and teachers' instructional quality could be regarded as adequate teachers' characteristics for brilliant academic performance.
\end{abstract}

Keywords: Academic performance, Senior School Certificate Examinations, Teachers' characteristics, Secondary school students.

\section{Introduction}

For many years, educators, administrators or managers, researchers have debated over which variables influence student's academic performance. A growing body of evidence suggests that schools can make a great difference in terms of students' academic performance and a substantial portion of that difference is attributable to teachers. Specifically differential teacher effectiveness is a strong determinant of difference in students' learning, far outweighing the effects of differences in class size and class heterogeneity. Students who are assigned to one ineffective teacher after another have significantly lower achievement and learning than those who are assigned to a sequence of several highly effective teachers. Thus the impact of teachers' effectiveness or ineffectiveness seems to be additive and cumulative. Which factors then contribute to teacher effectiveness? Certainly, there has been a convergence of the available research data pertaining to this question over the past years. Some of these factors fall under the general heading of teacher behavioural traits. Teacher behavioural traits are relatively stable traits that are related to, and influence, the way teachers practice their profession (UNESCO, 2004\}. Several of these traits have also been identified by other researches. Commitment and drive for improvement, for example, combine to form what Slavin (1995) referred to as relentlessness, and what Andersen and Pellicer (1998) termed zero tolerance for failure. Also confidence is similar to what Ashton and Webb (1986) termed self-efficacy. Despite differences in nomenclature, the teacher behavioural traits 
have been found to be related to teacher effectiveness and students academic performances in a variety of settings by a variety of researchers.

It is important to note however, that the influence of teacher behavioural traits on teacher's effectiveness and students ${ }^{1}$ academic performances is not direct. Rather it is moderated or mediated by their effects on the way in which teachers organize their classrooms and operate within them. What teachers are influences what teachers do. What teachers do, in return, influence what and how much, students learn (UNESCO 2004). So, effective teachers must possess the knowledge and skills needed to attain the goals, and must be able to use that knowledge and those skills appropriately if these goals are to be achieved. The possession of knowledge and skills fall under the heading teacher competence while the use of knowledge and skills in the classroom is referred to as teacher performance /productivity. Thus there should be a link between teacher behavioural traits, teacher competence, and teacher productivity and students academic performances.

Every educational system at every level depends heavily on teachers for the execution of its programmes. Obadara (2005) viewed teachers to be highly essential for a successful operation of the educational system and as a key to the educational development. Without teachers with relevant behavioural traits, educational facilities cannot be used to facilitate academic performance of students. Undoubtedly the success and quality of any educational system depend on the quality of teachers input into the system. Akanbi (2005) noted that it is a known fact that schools must have teaching and non-teaching personnel's. The question that arises is, what traits do the personnel's employed possess? The educational administrator by his position either in the ministry or in privately owned schools must equip the school with good and qualified teachers with relevant behavioural traits. The process of doing this according to him includes interview, test, recruitments, job analysis and record keeping. There must be training and development of academic staff. The training must aim at improving staff competences, teachers' productivity and students' academic performances including on the job training, workshops, seminars, etc. Also, the school administration should ensure that good personnel policies are formulated and implemented appropriately in the school. The staff must be motivated. This will make it easy to engineer the staff to be highly devoted to achieve the objectives of the school, education and the students. Many countries are in the midst of educational reform, with the heart of this reform revolving around changes in the curriculum and teacher instructional behaviour. Teachers play a central role in bringing about the desired reform, as it is the teacher who filters the curriculum through to the learners in (Sandt, 2007).

Unfortunately the present state of education in developing nations especially Nigeria does not allow anyone to have much confidence in the system. At all levels of our educational system, problems such as inadequate infrastructure, brain drain, population explosions, lack of motivation on the part of instructional and non-instructional staff, crowded classrooms, lack of instructional aids, lack of recreational facilities, high student/teacher ratio, inadequate training and development for staff and dearth of data and statistics. All these have serious implication on teachers' delivery system in the classrooms and certainly have undesirable effects on students' academic performance. Teachers with relevant behavioural traits have been recognised as the hearth and most vital resources in the educational system since they are the ones who interpret the aims and goals of education and ensure that the students are educated in line with them. Babayomi (1999) at the world Teachers' day noted that teachers are fully equipped to understand and communicate to both children and adults, the skills required to build more sustainable livelihood in a world in which technological change and globalization are continually changing the nature of work. High competence levels and recruitment criteria, career development, salaries comparable to other professionals with similar qualifications, appropriate class sizes and resources for effective teaching and learning are essential conditions for the educational quality that is universally sought. He identified the teacher with professional behavioural traits as the pivot of the educational process and the main determinant of the quality and effectiveness of its result. So the supply of good teachers with right traits remains the bottleneck to improvement. Odunusi (1999) stated that teachers with right traits are the hubs of any educational system upon their devotion and quality, the effectiveness of all educational arrangement must chiefly depend. Teachers have been, and will always be the essential pillars of education. No matter how grandiose a school system and its curricula may be, the implementation of its programmes will be fruitless unless competent and effective teachers handle them.

Therefore, the ultimate realization of the aims of education and thus, the achievements of the country's needs depends on the qualitative and quantitative attributes and attitudes of teachers in schools. In the classroom, a professional teacher must demonstrate excellence in his teaching. He must maximize his ability to transform the learners' positively in cognitive, affective and psychomotor areas. He must show superiority in his teaching process that is, what the teacher does, what the students do, the pattern of interaction etc. Personally, the teacher must be intelligent, well qualified and must possess neat appearance, and desirable traits. In essence, an effective teacher is a teacher who consistently, and rightly conducts a teaching learning interaction to the satisfactory achievement of desired (as well as 
the undesired but worthwhile) intent as well as the values of the process, the satisfaction of the interest groups based on professionally justifiable standards, ethnics and ideals with a measure of commendable creativity.

Researchers have been able to estimate the overall contribution of teachers' behavioural traits to students' academic performances. This includes not only the effect of easily measured attributes such as demography and qualification such as experience and degrees obtained but also the effect of harder to measure intangible attributes, such as teachers' attitude and skill in conveying knowledge. Araoyinbo (1995) pointed out the important role that the sex of the teacher plays as a pervasive influence in classroom relationships among other things. He established that the teachers' sex has an effect on his perception of the students' aspirations and attitudes and on his/her involvement in the job of teaching itself. He noted that, male teachers differ from female teachers in personality and social traits. The male teachers are much more emotionally stable and businesslike, but less friendly and responsible than their female counterparts. Other researchers have also confirmed that when these characteristics were present in a teacher,, Students' achievement would definitely be high.

Content based pedagogical knowledge (Sandt, 2007) can be described as practical knowledge of teaching. It includes knowledge of approaches to school topics, teachers' knowledge of teaching procedures such as effective strategies for planning classroom Practices, behavioural management techniques, classroom organizational procedures, motivational techniques, different ways of presenting facts. He described pedagogical knowledge of teachers as of special interest because it identifies the distinctive bodies of knowledge for teaching. It represents the blending of content and pedagogy into an understanding of how particular topics, problems, or issues are organized, represented, and adopted to the diverse interests and abilities of learners and presented for instruction. Pedagogical content knowledge is the category most likely to distinguish the understanding of the content specialist from that of the pedagogue.

Teachers therefore have been identified as the heart of the educational process and the main determinant of quality and effectiveness of its result. That the main bottleneck to improvement of students academic performances is recruitment of good and quality teachers. He noted that teacher's behaviour is not only influenced by their beliefs but also by their attitudes towards teaching. And that attitude is defined as internal beliefs that influence personal action and is learned indirectly through one's experience and exposures. Teachers' attitudes toward teaching include: Work value, teacher self esteem, teachers' self-efficacy, teachers' expectation, teachers' commitment etc. Attitudes teachers hold regarding students could be attitudes toward individual learners, groups or classes of learners. This could include liking (affection towards learners) enthusiasm to teach these specific learner(s). Teachers are more likely to exhibit more enthusiasm in preparation and presentation of lessons when they are affectionate towards learners than when they are apathetic or indifferent towards this student. These attitudes towards students could be formed due to characteristics exhibited by the students (such as low socio-economic status, poor discipline, physical appearance or special educational needs e.g. speech difficulties (Dada \& Alani, 2007) that teachers personally find acceptable or unacceptable or attractive or repulsive.

The validity of the hypothesis that, the work value held by individuals in an organization constitutes an intervening variable between performance and job satisfaction is no longer a matter of conjecture or debate. Morse postulated that the extent and nature of job satisfaction experienced by a person on his/her job is a function not only of the objective properties of the job but also of that person's motive or goals. In conformity with that view, God/harp and his colleagues of the social action school of thought argue that the issue of job satisfaction cannot be meaningfully understood without knowledge of the meanings, which individuals give to their work. An employee's value system or teachers work value has been argued to be central to his motivational system, to his expectation of organizational rewards and ultimately to his job performance and satisfaction. These serve as reference points of behaviours on the job.

Work values differ from person to person and such variations in work values are said to be due to a number of variables such as socializations and other types of life experience which have been in existence prior to the person's taking up the job; non-work social roles; and the work experiences themselves (Ejiogu, 1992). In a study \{Ejiogu, 1980\} of teachers' work orientations, teachers were revealed as placing higher values on the extrinsic reward of their jobs than on the intrinsic. The teachers, regardless of their variations in age, sex and qualifications placed the highest valuation on economic returns. They presented themselves as hedonistic and acquisitive creatures interested mostly in obtaining the greatest economic rewards. Certainly it would be sheer romanticism to expect the present day teachers in relatively deprived society such as Nigeria to work for a reward in heaven". The protestant ethic which emphasizes hard work as a sign of God's favour does not seem to appeal any longer to most of the modern employees, teachers inclusive.

It is crystal clear that the presence of financial and material resources alone cannot get things done except human beings are available with the necessary staff to make use of money and machine. In the school setting, goals and objectives are achieved through the efforts of people; knowledge could be imparted if human resources are present even 
when material resources are not available or adequate. It also pertinent to say that teachers are indispensable human resources out of all the human resources in educational system, This is so because teachers interpret the aims and goals of education and ensure that the children are educated in accordance with them. Since quality output depends on quality input, the success and quality of any educational system depends on the quality of teachers input into the system (Obadara, 2006). The concept of teachers' behavioural traits, teachers' productivity and students' academic performance are multi-dimensional. They involve an inter play of various elements in the work force. While the output may be related to miscellaneous resources or input, there are several productivity ratios, each of which is influenced by an array of relevant factors. These influencing factors include availability and quantity of materials or inputs, rate of capacity utilization, the scale of aspirations, the nature of equipments, the attitude and skill level of the work force and motivation of the teachers interplaying with the effectiveness and efficiency of the management.

The way in which these elements interact has an important impact in the resulting productivity of the teachers' and, the academic performance of students. Thus the level of realization depends on him or teachers' performance and technical factors. These are moderated by managerial action such that it is only through an effective intervention of able management that the full benefit of either or both factors can be drawn out to enhance productivity of teachers' and students academic performances (Ndu, 1987). There is therefore the need to identify and favorably modify all the factors and situations that prompt students' academic performance. In this way, the colossal investments in education by both public and private sources will neither be a waste nor dreams for national development, otherwise qualitative education remains a mere wish (Ogunsola 1991).

It thus appears that teachers' behavioural traits such as demographic traits, qualification, teaching process, teaching attitude and job satisfaction are important variables in teachers' productivity and students' academic performances. However, a critical examination of the-available literature revealed that previous researches despite their scope and perhaps depth only examined partially the relationship between demographic attributes of teachers as they relate to students leaning outcome which are extrinsic with utter disregard to intrinsic variables such as teachers' attitude, teachers' job satisfaction etc. For example in a study of A path-analytic study of some teacher characteristics and teacher job performance in secondary schools, the researcher concentrated more on demographic and qualification variables of the teacher. More attention was given to teachers' qualification and demographic variables in other study titled school. Environment, teacher characteristics, and teaching process as factors of teachers' productivity in selected unity schools.

The preceding literature review shows that none of the researchers studied the joint contributions of teacher behavioural traits such as demography, teaching process, teachers' attitude, job satisfaction and students academic performance exhaustively. However there is need for comprehensive approach. In addition, it has been observed that few researches have been devoted to exploring the influence of teacher behavioural traits on the students' academic performance while those that even exist concentrate largely on demographic correlates as a major component in their studies. The researcher also contends that the battery of predictor used to predict the student-academic performance in public secondary schools may be dissimilar in private secondary and from state to state in southwestern Nigeria. . The researcher therefore strongly contends that hardly any work exists that studies the joint Contributions of teachers behavioral traits-demography, teaching process, teaching attitude, job satisfaction, on students' academic performance in secondary schools exhaustively especially at the multivariate level in southwestern Nigeria. And the choice of southwestern geo- political zone of Nigeria is justified because the zone has the highest number of secondary schools both public and private. It therefore seems that this is one of the areas, which have not drawn much research interest in adequate measure in Nigeria, A few researchers ( Oluwole and Aremu, 2005) have shown interest in combined influence of intrinsic behavioural traits such as teacher work value, self-esteem, and job satisfaction and extrinsic teacher behavioral traits such as demographic traits on teachers' productivity and students academic performance. Many studies attest that some teachers contribute more to their students' academic growth than other teachers. However, research has not been very successful at identifying the specific teacher traits and classroom practices that are most likely to improve students' learning. Unfortunately, this is just the information that educational policymakers need most. This justifies the desire to break this ground so as to extend the frontier of knowledge in order to help improve the unimpressive, teachers' behavioural traits, teachers productivity and students leaning outcomes and serves as the motivating factor for undertaking the present piece of research so as to fill the-existing important research gap.

\subsection{Statement of the Problem}

The standard of education seems to be falling fast due to perceived low productivity of teachers, students and gross under-funding in secondary schools. This is due to poor performance of secondary school students in public 
examinations such as WAEC, NECO. JAMB etc. on yearly basis. Findings have supported the fact that certain teacher, school and home factors play a pact in determining students' academic performance through studies on teachers' variables, students and classroom variables singly or in combination so. as to enhance students academic performance have not yielded the expected significant result as evidenced in various WAEC, NECO, JAMB yearly result analysis. The hue and cry about the students' academic performance in Secondary School Certificate Examination is becoming alarming. The degree of failure is giving the general public a serious concern. The expected quality has not been attained. There is a persistent decline in the academic performance of Secondary School students in spite of government huge expenditure on education. However, instead of looking into the general and specific causes of decline, some, most of the time castigate the school related factors especially the teacher-related factors; knowing well that functional educational system depends on the adequacy of some indispensable teacher behavioural traits. So, there is a need to ascertain what teacher-variables influence the academic performance of secondary school students. It is against this background that the as teachers' teaching attitude, teachers' teaching process) and students' academic performance among secondary school students in Saki west local government of Oyo state, Nigeria.

\subsection{Purpose of the Study}

The main purpose of this study is to determine the extent to which teachers' behavioural traits relate to students academic performance in secondary schools in Saki west local government of Oyo state, Nigeria. Since the quality and quantity output of the educational system depend on the teachers' input into the system, the study therefore intends to use its findings to make useful recommendation for the accomplishment of secondary school goal. Specifically the study seeks to:

1. Find out the relevant traits in teachers that could positively influence the students' academic performance in secondary schools in Saki-west local government area of Oyo state.

2. Investigate the composite and relative contributions of teachers' behavioural traits such as teaching process and teaching attitude etc. to students' academic performance in Saki-west local government area of Oyo state.

\subsection{Significance of the Study}

The study is significant and the findings would benefit every stakeholder in education. The beneficiaries include the teachers, school management, parents, and students, ministries of education, Educational researchers, nongovernmental Organizations and general society at large in that the solution that will be provided in this work will help to enhance academic performance of the students, if it will be used in the course of recruiting teacher. It will help the teachers to improve better on his teaching method in order to enhance good performance from his students. It will be useful and helpful to the policy makers especially the curriculum developer, inspector of education, examiners etc. by enabling the curriculum developer to know how to frame and design topics in a way that will also enable them to correct and improve the performance of the student by appraising the teaching methodology employed.

\subsection{Scope of the Study}

The geographical scope of this study is one of eight local governments that made up of Oke-ogun (Saki-west local government) area of Oyo state, Nigeria. It involved public secondary schools to determine the extent of relationship between teachers' behavioural traits (teaching process, and teaching attitude) and students' academic performance. The principals, secondary school teachers and senior secondary school three (SSS 3) students were included. The students' results of West African Senior Secondary School Examination (WASSCE) conducted by West African Examination Council for the period of ten years, 2001 to 2010 were used to measure students' academic performance in senior secondary schools in terms of graduation rate.

\subsection{Research Design}

The study adopted descriptive research design of correlational type. The researcher was interested in knowing whether there would be relationships between the independent variables and the dependent variable without necessarily manipulating the independent variables. Here the dependent variable, which is academic achievement, is been paired with the independent variables (teachers characteristics) to know both their joint and relative predictive values. 


\subsection{Population}

The population of the study consisted of all the principals, teachers and SSS3 students that have passed out since 20012010 within the Saki west local government area of Oyo state. The population of the teachers in the surveyed local government was 2456 .

\subsection{Sample and Sampling Procedure}

A sample of 718 principals and teachers in the selected secondary schools were chosen. The sample consisted of 511 males and 207 females. The average age of the participants was 42.63 years and with standard deviation of 2.96 years.

\subsection{Participants}

The SSS3 students were considered in this study because of the uniformity and standardization of the instruments used in the assessment of the students as measure of academic performance. Also, the Principal and classroom teachers were also considered in this study. Since the study involved the teachers and their characteristics.

\subsection{Data Collection}

Data pertaining to teachers were collected from the schools of the sampled teachers using 'Teachers' Characteristics Scale" and the performance of the students in the SSCE were equally retrieved from WAEC master results paper sent to each schools which serves as academic performance. Also, data were collected on the basis of the subgroups involved in the study. The subgroups were principals, teachers and students on male and female basis. The students results covers a period of ten years from 2001-2010.

\section{Data Analysis}

Data obtained from the study were statistically treated to determine both the joint and relative contributions of the independent variables on the dependent variables. The two basic statistical methods used were Multiple Regression Analysis; and Pearson Product Moment Correlation.

\subsection{Results}

Research Question One: Are there significant relationships among the independent variables (teachers' academic qualification, teachers' content knowledge, teachers' instructional quality, teachers' evaluation procedures and teachers' job satisfaction) on academic performance among secondary school students in Saki-west local government area of Oyo state, Nigeria?

Table 4.1: Summary of Test of significant Correlations among Independent Variables and Students' Academic Performance.

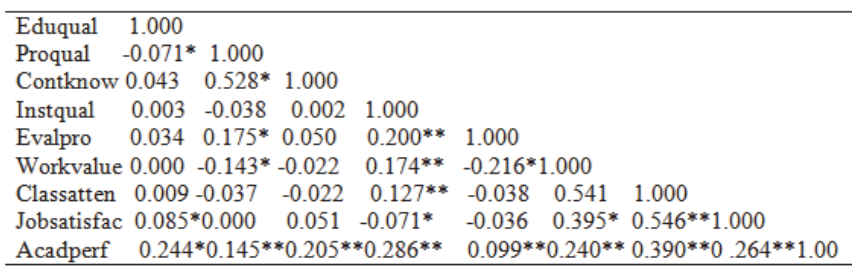

** Correlation Significant at 0.01

* Correlation Significant at 0.05

The results from table 4.1 showed that there was a positive and significant relationship between teachers' academic qualification, teacher's content knowledge, teacher's instructional quality, teachers' evaluation procedures and teachers' 
job satisfaction on student's academic performance among secondary school students in Saki-west local government area of Oyo state, Nigeria. Students academic performance had significant correlation with educational qualification $(r=$ $0.244, p<0.05)$, with professional qualification $(r=0.145, p<0.05)$, content knowledge $(r=0.205, p<0.05)$, instructional quality $(r=0.286, p<0.05)$, evaluation procedure $(r=0.099, p<0.05)$, work value $(r=0.240, p<0.05)$, classroom attendance $(r=0.390, p<0.05)$ and job satisfaction $(r=0.264, p<0.05)$ of the respondents respectively.

Research Question Two: To what extent would the joint contribution of the independent variables predict students' academic performance among secondary schools in Saki West local government of Oyo state, Nigeria?

Table2: Summary of Regression Analysis of the combined prediction of students' Academic Performance by the eight independent variables.

\begin{tabular}{|c|c|c|c|}
\hline R & R Square & Adjusted R Square & Std. Error of the Estimate \\
\hline 0.739 & 0.553 & 0.546 & 11.02166 \\
\hline
\end{tabular}

Summary Regression Anova

\begin{tabular}{|c|c|c|c|c|c|c|}
\hline & Sum of Squares & Df & Mean Square & $F$ & P & Remark \\
\hline Regression & 52835.76 & 8 & 6604.47 & 47.48 & 0.000 & sig \\
\hline Residual & 98760.76 & 710 & 139.10 & & & \\
\hline Total & 151596.52 & 718 & & & & \\
\hline
\end{tabular}

Table2 showed that the prediction of all the eight independent variables to the dependent variable. That is, students' academic performance correlated positively with the eight predictor variables. The table also shows a coefficient of multiple correlations $(R)$ of 0.739 and a multiple adjusted $R$ square of 0.546 . This means that $54.6 \%$ of the variance in the students' academic performance is accounted for by all the eight predictor variables, when taken together. The joint contribution of the independent variables to the dependent variables was significant $(F=47.48 ; d f=8 ; 710: p<0.05)$ and that other variables not included in this model may have accounted for the remaining variance.

Research Question Three: What is the relative effect of each of the independent variables on students' academic performance among secondary school students in Saki-west local government area of Oyo state, Nigeria?

Table 3: Relative contribution of the independent variable to the dependent variable ( Test of significance of the Regression coefficients).

\begin{tabular}{|l|c|c|c|c|c|c|}
\hline & \multicolumn{2}{|c|}{ Unstandardized Coefficients } & Standardized coefficients & \multicolumn{3}{|c|}{} \\
\cline { 2 - 7 } & $\mathrm{B}$ & Std.Error & Beta & $\mathrm{T}$ & $\mathrm{P}$ & Remark \\
\hline Constant & 21.679 & 3.050 & & 7.107 & 0.000 & $\mathrm{Sig}$ \\
\hline Academic qualification & 0.445 & 0.439 & 0.031 & 5.696 & 0.356 & $\mathrm{Sig}$ \\
\hline Professional qualification & 0.031 & 0.042 & 0.089 & 1.767 & 0.670 & $\mathrm{NSig}$ \\
\hline Trt content knowledge & 0.544 & 0.074 & 0.072 & 7.692 & 0.018 & $\mathrm{Sig}$ \\
\hline Trt. Instructional quality & 0.531 & 0.071 & 0.274 & 12.767 & 0.000 & $\mathrm{Sig}$ \\
\hline Trts. Evaluation procedure & 0.405 & 0.078 & 0.212 & 3.924 & 0.000 & $\mathrm{Sig}$ \\
\hline Trts. Work value & 0.107 & 0.064 & 0.189 & 0.768 & 0.650 & $\mathrm{NSig}$ \\
\hline Trts. Classroom attendance & 0.056 & 0.079 & 0.030 & 1.714 & 0.476 & $\mathrm{NSig}$ \\
\hline Trt. Job satisfaction & 0.176 & 0.075 & 0.035 & 0.2 .369 & 0.003 & $\mathrm{Sig}$ \\
\hline
\end{tabular}

Table 3 reveals the relative contribution of the eight independent variables to the dependent variable, expressed as beta weights. The positive value of the effects of teachers' academic qualification, teachers' content knowledge, teachers' instructional quality, teachers' evaluation procedures and teachers' job satisfaction implies that the students' academic performance is actually determined by positive reinforcement of these eight variables. Using the standardized regression coefficient to determine the relative contributions of the independent variables to the explanation of the dependent variables teachers' content knowledge made the most significant relative contribution to the prediction of academic performance $(B=0.544, t=7.692, p<0.05)$; followed by teachers instructional quality $(B=0.531, t=12.767, p<0.05)$; teachers academic qualification $(B=0.445, t=5.696, p<0.05)$, followed by teachers evaluation procedures $(B=0.405, t=3.924$, 
$p<0.05$ ) and then, teachers job satisfaction $(B=0.176, t=2.369, p<0.05)$. However, teachers' professional qualification ( $B$ $=0.031, t=1.767, p>0.05)$ followed by teachers work value $(B=0.107, t=0.768, p>0.05)$ and teachers classroom attendance $(B=0.056, t=1.714, p>0.05)$ were not potent predictors of academic performance of secondary school students in Saki-west local government area.

\subsection{Discussion of the Findings}

The result of research question 1 shows that $54.6 \%$ of the variance in students' academic performance of secondary school students in Saki west local government is accounted for by the teachers' characteristics. The F-value is 47.48 which is significant at $P=0.05$ shows that the effect is still significant. Luster and McAdoo (1994) found that differences in teachers' characteristics are responsible for students' academic performance. Aber (1994) Adetona (2005) and Ukwueze (2007) also corroborate the result by noting that teachers' characteristics affect academic performance. The result explains the need to look beyond one variable as accounting for either low performance or high achievement.

The result in relation to research question 2 shows that, the relative contribution of each of these independent variables on students' academic performance among the secondary school students in the study, the teachers content knowledge made the most significant relative contribution to the prediction of academic performance followed by teachers instructional quality; teachers academic qualification, followed by teachers evaluation procedures and then, teachers job satisfaction in that order. This shows that cognitive factors appear as the most potent contributor to academic performance of secondary school students in Saki west local government. This means that cognitive factors of the teachers' variables are most important than any other factors in predicting the academic performance of the participants. This finding corroborate Jansen (1996) and Hulst and Janean (2002) who discovered that, teachers' factors have significant impact on students' academic performance. Also, this finding is against the finding of Trueman and Hartley (1996) who found that students factors is more significant in predicting students' academic performance.

\subsection{Implications for the Counselling and Educational Practice}

The findings from this study have revealed the need for counselors, teachers, psychologists and other stakeholders of education to take into account the variables considered in this study while addressing secondary school students' academic achievement problems. Making the educational stakeholders aware of the teachers' factors that are important to high academic performance of secondary school students.

Teaching Service Commission recruiting teachers into secondary school system has a significant role to play. The professional where-with-all lies with them and the onus are on them to identify this factors as it affects students' academic performance.

To ensure high academic performance, competence, adequate and qualified teachers with teaching experience should handle the students' right from the secondary school level. If these were done, it would go a long way to enhance high academic performance and reduce examination malpractices in the Nation's Public examinations.

\section{Conclusion}

The cognitive and non-cognitive variables considered in this study could be used to predict and facilitate academic performance among secondary school students. The high achievement or failure rate stems from a post pourri of factors some of which have been studied in this work.

The study has revealed that, a student may have more than one reason for the poor academic performance and that a quick intervention will lead to the identification of the factors responsible and find solution to them.

This indicates that, training of teachers should be look into and that only qualify and competent teachers should be employed into secondary schools only this can guarantee the nation, the expected development and growth. In place of lamentation and all education stakeholders should move to action. 


\section{References}

Adeyemo, D. A. 2010. Educational transition and emotional intelligence, moving stories around the world, Edited by Divya Jindal-Snape pp.33-47.

Aber, C.V. 1996. Brown S. D. and Larkin, K. C. 1989. Self-efficacy as moderator of scholastic aptitude- academic performance relationship. Journal of Vocational Behavioural35, 64-75.

Akanbi, J.O. 2005. How to study and pass important examinations: A psychological Approach. Ibadan: Maritime Printers.

Araoyinbo, A. V. 1994. A causal model of some socio-psychological variables as determinant of learning achievement in secondary school social Studies. PhD thesis, Institute of Education. University of Ibadan.

Andersen, R. E. and Pellicer, J.K. 1998. A prospective longitudinal study of psychological predictors of achievement. Journal of SchoolPsychology, 34(3), 285 - 306.

Babayomi, O.A. 1999 Grade-related changes in the school Environment. Effects on Achievement Motivation. In advances in motivation and Achievement, vol. 3: 155

Dada, E.D. and Alani, P.J.(2001) Grade-related changes in the school Environment. Effects on Achievement Motivation. In advances in motivation and Achievement, vol. 3: 155

Ejiogu, M. O. 1992 Age-of-acquisition, word frequency and neighborhood density effects on the development of spoken word recognition and phoneme awareness. Journal of memory and lal1guage, 45, 68 - 492.

Fehintola, J.O. 2011. Analysis of Students' perceived and actual Weaknesses as Correlates of Performance in Mathematics in Senior Secondary School Certificate Examination in Oyo state, Nigeria. Nigerian Journal of Applied Psychology vol12/13,No2/1, 211229.

Johnes, E.E. 1990. Student-identified Stresses that relate to College life. Paper presented at the annual conference of the American psychological Association, Toronto, Canada, and August 1978. ED 170.630.

Jansen, A. (Ed), Mass Failure in Public Examinations. Causes and Problems. Heinemann Educational Books Nig. Ltd., Ibadan.

Kapur, J. P. 1972. Changes in Science Education and Achievement (1970 - 1984). Oxford Pergamon Press.

Ndu, S.A. 2002. Middle-grade predictors of students' motivation and behaviour in high school. Journal of Adolescent Research, 15,327 352.

Obadara, N.O. 2005; A prospective longitudinal study of psychological predictors of achievement. Journal of SchoolPsychology, 34(3), $285-306$.

Odunusi, M.A. 1999 Essential elements of strong parent Involvement programs. Educational Leadership, 47, 18-20.

Ogunsola, T.A. 1991. The Impact of family background factors on Academics.

Pajares, F. 1996; Self-efficacy Beliefs in academic setting. Eeducational Review.

Pajares, F. 2002. Overview of Social Cognitive Theory and of Self-Efficacy. Retrieved May 2007, from http://www.emory.edu/EDUCATION/mfp/eft.html.Pajares, F. 1996. Self-efficacy beliefs in achievement settings. Review of Educational Research, 66, 543-578.

Richards, C.S. and Wilson, M.A.1961. Behaviour Modifications of Studying through Study Skills Advice and Self- control Procedure. Journal of Counseling Psychology, 22(5) 431 - 436.

Salami, S. A, 2004. Secondary Education programme Under the New National policy on Education. An assessment based on the Senior Secondary School certificate examination. A paper delivered at West African Examination Council Seminar.

Slavin, D.H. 1995. Self-Efficacy, Education and Instruction. In J.E. Maddux (Ed) Self-efficacy, Adaptation, and Adjustment: Theory, research, and application (pp. 281 -303): New York: Plenum Press.

Sandt, S. 2007. Effects of maternal employment and non maternal infant care on development at two and four years. Early Development and Parenting, 3(2), 113 - 123.

Salami, S.O. and Salam, M.A. 2005. Occupational Stress: Sources, degree and symptoms among lecturers in Nigeria. Research in Education 11, 121 - 132.

Tao, A., Dong, E., Pratt, P.J., Hunsberger, B., and Pancer, L.A. 2000.

Trueman, M.A.R. and Hartley, L. 1996. Classroom goal structures, social satisfaction and the perceived value of academic tasks. British Journal of Education Psychology 67, 1 -12.

UNESCO. 2004. Effects of Leaner; variable on Academic performance and Adjustment of Junior Students: Counselling Implication for UBE programme. Counselling Association of Nigeria. Conference August 2007. 
ISSN 2239-978X

ISSN 2240-0524
Journal of Educational and Social Research MCSER Publishing, Rome-Italy
Vol. 4 No. 6 September 2014 